\title{
Mating types of Phytophthora colocasiae on the island of Upolu, Samoa
}

\author{
Kieran D. Mellow ${ }^{1, \star}$, Joy L. Tyson ${ }^{1}$, Robert A. Fullerton ${ }^{1}$, Angelika Tugaga ${ }^{2}$, Fa'alelei \\ Tunupopo ${ }^{3}$ and Amy Maslen-Miller ${ }^{2}$ \\ ${ }^{1}$ The New Zealand Institute for Plant \& Food Research Limited, Private Bag 92169, Auckland, \\ 1142, New Zealand \\ ${ }^{2}$ The Scientific Research Organisation of Samoa, Apia, Samoa \\ ${ }^{3}$ Samoa Ministry of Agriculture and Fisheries, Apia, Samoa \\ ${ }^{*}$ Corresponding author: Kieran.mellow@plantandfood.co.nz
}

\begin{abstract}
Taro leaf blight (TLB) caused by Phytophthora colocasiae is a damaging disease that destroyed Samoa's taro industry following its introduction in 1993. The aim of this study was to determine the occurrence of the $\mathrm{A}^{1}$ and $\mathrm{A}^{2}$ mating types of $P$. colocasiae for a more comprehensive understanding of the risk the pathogen poses for the future of the taro industry in Samoa. In September 2015, 54 isolates of P. colocasiae were collected from taro leaf blight lesions from 13 farms around the island of Upolu, Samoa. The mating types of each isolate was determined by observation of oospore formation when paired with tester isolates of Phytophthora nicotianae of known mating types $\left(\mathrm{A}^{1}\right.$ or $\left.\mathrm{A}^{2}\right)$. Fifty isolates were found to be $\mathrm{A}^{2}$ mating type and four did not form oospores with either mating type. No $\mathrm{A}^{1}$ or self-fertile isolates were found. These results suggest that the A1 mating type has not been introduced to the island of Upolu, preventing the formation of oospores between compatible mating types of $P$. colocasiae and lessening the risk of new and potentially more threatening genotypes of the pathogen from emerging through genetic recombination.
\end{abstract}

Keywords taro leaf blight, Colocasia esculenta, Phytophthora nicotianae, taro, sexual reproduction.

\section{INTRODUCTION}

Taro (Colocasia esculenta) is a staple food crop in Samoa and many other Pacific Island countries. The introduction of the heterothallic oomycete Phytophthora colocasiae to Samoa in 1993 led to food shortages and the destruction of Samoa's taro export industry (Chan et al. 1998). The pathogen causes taro leaf blight (TLB) and is present throughout Asia and the Pacific region. Hainan Island, China, is thought to be the centre of origin of the species (Zhang et al. 1994).

Breeding programmes based on recurrent selection of taro were initiated in 1994 with the aim of developing cultivars resistant to TLB whilst maintaining desirable characteristics for consumers (Singh et al. 2012). This involved the recombination of selected TLB resistant individuals to achieve new resistant populations (Singh et al. 2012). The taro export industry in Samoa is recovering, and two cultivars developed in the breeding programme are currently being exported to New Zealand and the USA (pers. comm., Tauelii Mauga, Samoa Ministry of Agriculture and Fisheries, February 2018).

Heterothallic species of Phytophthora produce oospores in intra- or interspecific pairings of two compatible types (Ko 1979). Oospores can survive in a range of conditions for a long time and there is a possibility of new and more threatening genotypes of $P$. colocasiae emerging via sexual recombination. Therefore, the presence of two compatible mating types in Samoa would 
increase the risk the disease poses to the future of the country's taro industry.

A previous study investigating the occurrence of $P$. colocasiae mating types $\left(\mathrm{A}^{1}\right.$ and $\left.\mathrm{A}^{2}\right)$ in the Pacific region found that all five isolates tested from Upolu were $\mathrm{A}^{2}$ mating type (Tyson \& Fullerton 2007). However, further surveillance and more comprehensive studies investigating the occurrence the mating types present in Samoa were justified due to the threat that the introduction of the second mating type could pose. This study investigated the occurrence of the mating types of $P$. colocasiae from taro leaves within 13 farms around the island of Upolu, Samoa.

\section{MATERIALS AND METHODS \\ Isolate collection}

Fifty-four isolates of $P$. colocasiae were collected in September 2015 from taro leaves showing obvious symptoms of taro leaf blight on 13 farms around Upolu, Samoa. A map of the island indicating the location of the farms from which these isolates were collected is shown in Figure 1. Small pieces of the edge of an active TLB lesion, or clusters of sporangia from the edge of a lesion, were transferred to Petri dishes containing CARPP medium consisting of corn meal agar amended with $2 \mathrm{mg} / \mathrm{L}$ carbendazim, $250 \mathrm{mg} / \mathrm{L}$ ampicillin, $10 \mathrm{mg} / \mathrm{L}$ rifampicin, $5 \mathrm{mg} / \mathrm{L}$ pimaricin and $100 \mathrm{mg} / \mathrm{L}$ pentachloronitrobenzene (Tyson et al. 2014). This is a modified medium that is selective for oomycetes (Jeffers \& Martin 1986).

Two tester isolates of Phytophthora nicotianae

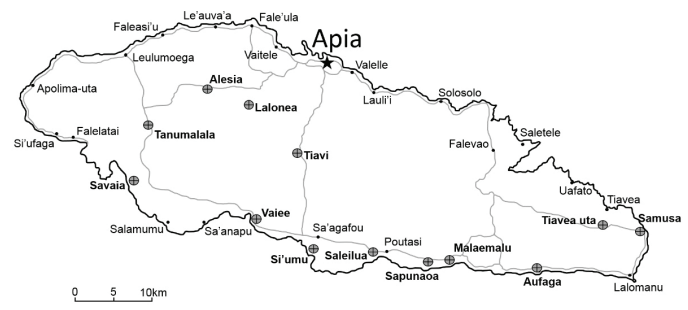

Figure 1 Map of the island of Upolu, Samoa. Grey crossed circles indicate the locations of Phytophthora colocasiae collection sites in 2015. were obtained from L.W. Timmer, University of Florida (P91-28 = mating type $\mathrm{A}^{1}$, Riv-1 = mating type $A^{2}$ ) in 2002 (Tyson \& Fullerton 2007). These $P$. nicotianae tester strains were preferred over any $P$. colocasiae isolates for consistency (previous studies using these tester strains for similar purposes) in addition to their availability and the reliability.

\section{Mating type testing}

Isolates were placed 10-15 $\mathrm{mm}$ apart on unclarified V8 juice agar (100 mL V8 juice, $2 \mathrm{~g}$ $\mathrm{CaCO}_{3}, 15 \mathrm{~g}$ agar, $900 \mathrm{~mL}$ distilled water) (Hine \& Aragaki 1963) and incubated in the dark at $25 \pm 1^{\circ} \mathrm{C}$. Two plates were prepared for each pairing.

Each isolate was paired with itself, and with $P$. nicotianae $\mathrm{A}^{1}$ and $\mathrm{A}^{2}$ mating types. In addition, the two $P$. nicotianae mating type isolates were paired with each other as a positive control. Plates were examined every 7 days for 4 weeks for the presence of oospores. Formation of an oospore was confirmed by observation of their thick cell wall and distinctive, amphigynous antheridia (Fig. 2).

This process was repeated three times for those isolates that did not form oospores with either of the P. nicotianae tester isolates.

\section{RESULTS}

Oospores formed between compatible isolate pairings after 2-3 weeks of incubation. A summary of the results is found in Table 1. In total, of the 54 isolates collected from the island of Upolu, 50 isolates produced oospores when paired with the $\mathrm{A}^{1}$ tester isolate of $P$. nicotianae, confirming they are $\mathrm{A}^{2}$ mating type. The remaining four isolates did not form oospores when paired with either of the tester isolates (neuter strains). None of the isolates were $\mathrm{A}^{1}$ mating type or self-fertile. 


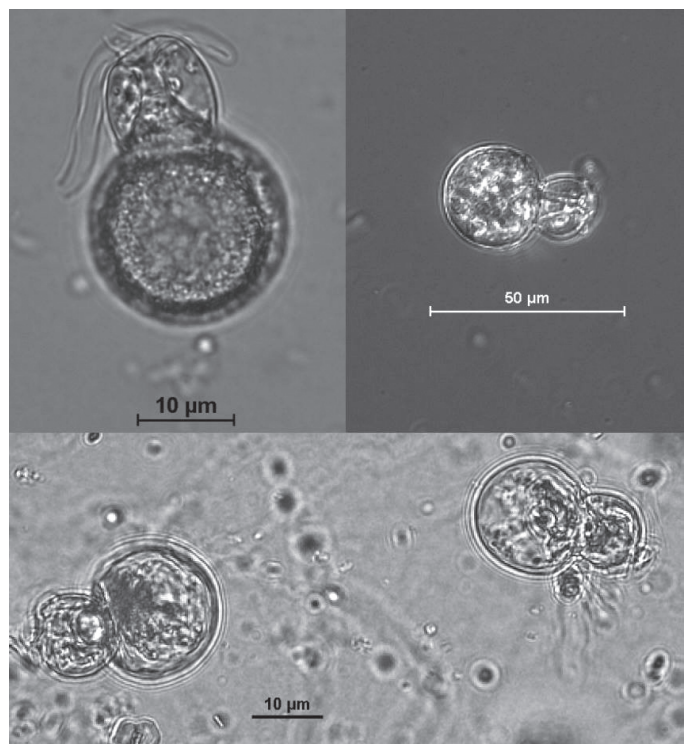

Figure 2 Oospores formed by the pairing of compatible mating types of Phytophthora colocasiae ( $\mathrm{A}^{2}$ mating type) and Phytophthora nicotianae ( $\mathrm{A}^{1}$ mating type).

\section{DISCUSSION}

The results from this study give a more comprehensive and detailed understanding of the occurrence of the $P$. colocasiae mating types on the island of Upolu, Samoa, and confirm that only the $\mathrm{A}^{2}$ mating type is present. These results are consistent with the findings from an earlier study (Tyson \& Fullerton 2007) that suggested the $\mathrm{A}^{1}$ mating type of $P$. colocasiae had not been introduced to Samoa at the time isolates were collected (1998). The 54 isolates tested in this study were collected from Upolu in 2015 , suggesting that the $A^{1}$ mating type was still absent from Samoa 17 years later.

$\mathrm{A}^{1}$ mating type isolates have been found in the Pacific region, indicating that the $\mathrm{A}^{1}$ mating type has spread from Asia, where it is thought to have originated and where it is abundant (Shrestha et al. 2014; Nath et al. 2015). An early study reported the presence of only the $\mathrm{A}^{1}$ mating type in Hawai'i (Ko 1979) and although later studies found only the $\mathrm{A}^{2}$ mating type in Hawai'i (Lin et al. 2004; Tyson et al. 2007), in 2014, Shrestha et al. (2014) found that two of 214 isolates from Hawai'i were $\mathrm{A}^{1}$ mating type.

Table 1 Summary of mating types of 54 Phytophthora colocasiae isolates from different locations on the island of Upolu, Samoa.

\begin{tabular}{lcccc}
\hline Location & $\mathrm{A}^{1}$ & $\mathrm{~A}^{2}$ & $\mathrm{~A}^{0 *}$ & Total \\
\hline Lalonea & 0 & 4 & 0 & 4 \\
Aleisa & 0 & 4 & 0 & 4 \\
Tanumalala & 0 & 3 & 1 & 4 \\
Savaia & 0 & 4 & 0 & 4 \\
Vaiee & 0 & 4 & 0 & 4 \\
Siumu & 0 & 4 & 0 & 4 \\
Tiavi & 0 & 4 & 0 & 4 \\
Saleilua & 0 & 3 & 0 & 3 \\
Malaemalu & 0 & 3 & 1 & 4 \\
Sapunaoa & 0 & 4 & 0 & 4 \\
Aufaga & 0 & 5 & 0 & 5 \\
Samusa & 0 & 5 & 0 & 5 \\
Tiavea Uta & 0 & 3 & 2 & 54 \\
Total & 0 & 50 & 4 & 5
\end{tabular}

${ }^{\star} \mathrm{A}^{0}$ refers to isolates that do not form oospores when paired with either mating type (neuter) 
$\mathrm{A}^{0}$ (neuter strains) mating types have been reported in Indonesia, Papua New Guinea, Hawai'i, and Thailand. The reason for the apparent loss of ability for these isolates to produce oospores is not clear. It is possible these isolates may indeed produce oospores under different conditions than used in this study.

Breeding programmes have been established to develop cultivars of taro that have with increased resistance to TLB and increased genetic diversity. However, the introduction of the $\mathrm{A}^{1}$ mating type of P. colocasiae into Samoa would constitute a risk to the country's taro industry. Sexual reproduction between $\mathrm{A}^{1}$ and $\mathrm{A}^{2}$ mating types would introduce a longer-lived form of inoculum due to the longevity and durability of oospores. Furthermore, genetic recombination between an introduced $\mathrm{A}^{1}$ mating type with the pre-existing $\mathrm{A}^{2}$ type would increase the chances of new and potentially more threatening genotypes of $P$. colocasiae emerging.

\section{ACKNOWLEDGEMENTS}

Collection of the Samoan isolates of Phytophthora colocasiae in 2015 was funded by the Pacific Horticultural and Agricultural Market Access programme (PHAMA). The research on mating types was partially funded by the Australian Centre for International Agricultural Research (ACIAR).

\section{REFERENCES}

Chan E, Milne M, Fleming E 1998. The causes and consequences of taro leaf blight in Samoa and the implications for trade patterns in the South Pacific region. Tropical Agriculture (Trinidad) 75(1): 93-98.

Hine R, Aragaki M 1963. Pathogenicity, vitamin nutrition and cultural characteristics of isolates of Phytophthora parasitica from carnation and other hosts in Hawaii. Phytopathology 53: 1194-1197.

Jeffers SN, Martin SB 1986. Comparison of two media selective for Phytophthora and Pythium species. Plant Disease 90: 1038-1043.

Lin M, Chen J, Uchida JY, Kadooka CY 2014. Mating type distribution, fungicide sensitivity, and phylogenetic relationships of Phytophthora colocasiae. Plant Protection Bulletin 56(1): 25-42.

Ko WH 1979. Mating-type distribution of Phytophthora colocasiae on the island of Hawaii. Mycologia 71(2): 434-437.

Shrestha S, Hu J, Fryxell RT, Mudge J, Lamour K 2014. SNP markers identify widely distributed clonal lineages of Phytophthora colocasiae in Vietnam, Hawaii and Hainan Island, China. Mycologia 106(4): 676-685.

Singh D, Jackson G, Hunter D, Fullerton RA, Lebot V, Taylor M, Iosefa T, Okpul T, Tyson JL 2012. Taro leaf blight - a threat to food security. Agriculture 2(3): 182-203.

Tyson JL, Fullerton RA 2007. Mating types of Phytophthora colocasiae from the Pacific region, India and South-east Asia. Australasian Plant Disease Notes 2(1): 111112.

Tyson JL, Taylor RK, Curtis CL, Manning MA 2014. A pre-harvest rot of persimmon fruit caused by Phytophthora cactorum in New Zealand. Australasian Plant Disease Notes 9(1): 122.

Zhang KM, Zheng FC, Li YD, Ann PJ, Ko WH 1994. Isolates of Phytophthora colocasiae from Hainan Island in China: evidence suggesting an Asian origin of this species. Mycologia 86(1): 108-112. 